\title{
AC 2010-951: PROPOSAL ADVICE: EXPERIENTIAL ADVICE FOCUSED FOR NEW FACULTY
}

\section{Adrienne Minerick, Mississippi State University}

Adrienne Minerick is an Associate Professor of Chemical Engineering at Michigan Technological University having recently moved from Mississippi State University, where she was a tenured Associate Professor. She received her PhD and M.S. from the University of Notre Dame and B.S. from Michigan Tech. At Tech, Adrienne has taught Advanced Kinetics. At MSU, she taught graduate Chem Eng Math, Process Controls, Intro to Chem Eng Freshman Seminar, Heat Transfer, and Analytical Microdevice Technology courses. She is an NSF CAREER Awardee and was the faculty advisor for MSU's NOBCChE chapter. Her research is in medical microdevice diagnostics \& dielectrophoresis. 


\title{
Proposal Advice: Experiential Advice Focused for New Faculty
}

\begin{abstract}
At the 2009 ASEE annual meeting, the New Engineering Educators Division and the Engineering Research Council jointly sponsored a session entitled, "2575: Funding Sources for Engineering Research." The author was one of the panelists invited to participate as the token faculty member just having earned tenure with both educational and research funding and publications. The author / panelist gave a talk on "Proposal Advice: Experiential Advice" which included a Top 10 list of Do's \& Don'ts to Earn Competitive Funding as a New Professor. The feedback from this presentation and subsequent discussion was positive and is reproduced here in a format accessible for all new engineering educators.
\end{abstract}

The advice provided is applicable to faculty writing proposals for educational research as well as scientific / engineering research. The primary focus is on competitive funding where experts and peers in the field evaluate the merits of the proposed idea and that feedback is provided to the proposer. Advice and strategies are outlined for working through rough periods and improving ideas and proposals to the level they are funded. While the perspectives provided are from one person's experiences and not officially endorsed by any funding agency, they are focused to provide encouraging and tangible advice on how new faculty can approach writing their first proposals and get them funded.

\section{Introduction and Brief Background of the Author}

A key mentor (my mother) told me as I was growing up, "You don't know what you don't know until you do know what you didn't know." This is apparently a slight misquote from Lewis Carroll's 'Alice's Adventures in Wonderland', but wise nonetheless. The issue is that when one doesn't know what they don't know, they also don't know what questions to ask or who to ask them of to find the answers they need to move forward. This is extremely true of beginning assistant professors in academia. While there are some necessary commonalities that will earn a person tenure at most schools (publish, get funding, publish), the playing field is different at each institution.

This paper seeks to provide the proposal writing advice I wish I had as I transitioned from being a freshly graduated $\mathrm{PhD}$ to a tenured Associate Professor. I began as Assistant Professor in August 2003 at Mississippi State University after having defended my Ph.D. in July 2003 at the University of Notre Dame. I had read many of the new faculty advice books ${ }^{1-16}$ and was determined to be a 'quick starter'. I volunteered for entirely too many service activities, designed graduate recruiting brochures and other activities, all of which yielded positive feedback from my colleagues, but no real tangible measurable credentials to help my annual reviews and thus earn tenure. In retrospect, I was intimidated by writing research proposals, didn't exactly know how to structure a proposal and lacked confidence that my ideas were good. During that first year, I only tried for smaller proposals and never stuck my neck out very far. When I got negative reviews, I felt devastated and defeated. Just as students sometimes allow grades to reflect their self-worth, I was letting feedback tell me I wasn't good or worthy of the job. As a new faculty member, maybe the baggage that holds you back is a little different, but a 
key change needs to occur that allows you to view the proposal writing process as an iterative game which in most cases yields stronger, better conceived, more scientifically solid research ideas. The whole process is a fun challenge that you sometimes win and when you lose, there is so much to learn from it - and after all, isn't continual learning one of the attributes that drew us into academia?

Now, why do I feel qualified to write this paper $6 \frac{1}{2}$ years later? To be honest, I still battle that imposter syndrome ${ }^{17}$. However, I earned tenure / promotion to Associate Professor in August 2009 and was recruited heavily by a new institution with an offer that could not be refused, so moved there as an Associate Professor starting January 2010. I earned a CAREER Award in 2007 as well as new faculty awards from Oak Ridge Associated Universities (ORAU), ASEE's Southeast section, Outstanding Paper Awards, Academy of Distinguished Teachers, and my students have earned over 18 awards in research. I've been invited to write perspective articles, had my research featured on the cover of a journal, invited to write book chapters, and my group's publications are being cited more each day. Since 2003, I've helped secure a total of $\$ 2,149,859$ in both research and educational funding.

Most funding has come from the National Science Foundation. I submitted (as a co-PI) my first proposal in summer 2004. I was a Research Experience for Undergraduates (REU) site proposal and was funded in December 2004. Batting 1000 is not typical, but the PI and I spent the entire summer planning and writing the proposal. It was so polished and had been internally reviewed by so many people that I now understand that is the minimum that new faculty need to target. I then had a Small Grant for Exploratory Research (SGER) funded in 2006 (NOTE: these are now Grants for Rapid Response Research (RAPID) and EArly-concept Grants for Exploratory Research (EAGER)). My second submission of the CAREER award was funded in 2007 (plus 5 supplements), and a Course, Curriculum, and Lab Improvement (CCLI) proposal (NOTE: these are now Transforming Undergraduate Education in Science, Technology, Engineering and Mathematics (TUES)) was funded in 2008 / 2009. A small equipment proposal was funded in 2009 followed by a larger Major Research Instrumentation (MRI) proposal in 2009. The very first proposal I ever had funded was in late 2003 and was USDA funding via a State Agency. The whole opportunity arose from a collaborative contact made during a university trip. Additionally, my group received non-competitive (congressionally mandated) funding from DOE's Sustainable Energy Research Center at Mississippi State University. A small amount of funding came from the National Institutes of Health to fund a special symposium for 2 years, but this is a major area where I need to focus writing proposals. Miscellaneous funding has included ORAU, a Research Initiation Proposal, National Institutes of Standards and Technology (NIST) REU, and Academy of Applied Science. The list of not funded proposals is much, much longer. It includes multiple submissions to the NSF, DOE, DARPA, NASA, American Meat Association (AMA), National Academies Keck Futures Initiative, Camille and Henry Dreyfus Foundation, Sun Grant (Tri-state initiative), Sloan Foundation, Life Sciences Biotechnology Institute (LSBI) and others. Some of these ideas have been recycled, improved and eventually received funding. Each submission has been a learning experience and I haven't found a greater sense of accomplishment than when the submit button is finally hit.

All these experiences have led to the following Top 10 list of Do's \& Don'ts to Earn Competitive Funding as a New Professor. The advice provided is applicable to faculty writing

Proceedings of the 2010 American Society for Engineering Education Annual Conference \& Exposition Copyright@2010,American Societyfor Engineering Education 
proposals for educational research as well as scientific / engineering research and is written to be accessible to all new engineering educators. The overarching message is intended to be a positive one that empowers the new faculty to utilize feedback and grow to secure the funding they seek. The perspectives provided are from one person's experiences and not officially endorsed by any funding agency. The goal is to provide encouraging and tangible advice on how new faculty can approach writing their first proposals and get them funded.

\section{The Top Ten Do's \& Don'ts to Earn Competitive Funding as a New Professor}

\section{\#1: Do over prepare the project idea and proposal}

Preparation is essential. Do an extensive literature search and include it in the proposal. This demonstrates your command of the field and allows you to contextualize your own new, novel idea within the field. It is important to directly state how your proposed idea will contribute to the knowledge in the field. Write frequently on the proposal, revise what you wrote as new sections are added, and write some more. The goal is to produce a well-written, informative, and easy to read research (education) plan that is easily understood by an expert in your field as well as by someone tangentially related to your field.

\section{\#1: Don't assume connections between concepts are apparent}

A common mistake when writing is to talk around a main point by saying why it is important and what information will be attained without explicitly saying what you are doing. This is so important that it should actually be repeated in a couple of places in the proposal. It is important to organize carefully to reiterate important points and to directly tell the readers that it is related to another aspect of the proposal and how. The rule of thumb I use is to state important ideas in the introduction, expand on them in the body, and restate them at the end of the proposal, either in a timeline or in a concluding section.

\#2: Do get feedback from experienced individuals that you trust and respect Experience is invaluable in writing competitive proposals. Get feedback from someone not directly in your field who has recently been successful at getting funding from the same agency. Also get feedback from an expert in your field. This will ensure that your proposal is accessible to all types of reviewers. Provide each reviewer a set of questions that you'd like him or her to answer. One basic question to ask is to have them summarize their understanding of what you have proposed. If they have any misunderstandings about certain sections, you know that you need to rewrite these to be clearer. It is a good idea to set up an appointment to discuss their feedback two days after you receive it. This two day waiting period is important because it allows you to think about the feedback and be objective about changing your work.

\#2: Don't be so protective of your idea that you lose opportunities to discuss and improve upon it Every idea has shortcomings. Recognizing this is challenging, but it allows one to improve the idea. While different reviewers may recognize the same shortcoming, they may differ in their advice about how to improve it. Proposal writers learn to scrutinize reviewer's comments in order to accurately identify the root shortcoming in a proposal. Most colleagues have admirable intentions, want to help, and won't take your idea. In the end, you'll gain more from being open than from being protective and closed. 
\#3: Do take advantage of as many opportunities as possible

Whenever a funding opportunity crosses your desk, seriously consider how you can adapt what you do to that request for proposals. Funding can come from places you may not expect. Once a person is established, they can be more selective in the opportunities that they pursue, but new faculty usually won't excel with a selective attitude. The probability of securing funded goes up with the number of pending proposals (provided you did \#1 \& \#2). In fact, I try to have at least one proposal pending, one proposal in preparation, and one in revision at all times during the year (and one manuscript under review, one in preparation, etc. too!).

\#3: Don't allow collaborative projects to take precedence over your individual / lead projects This is a difficult thing to do. We all don't want to say no or let our colleagues down. In addition, while on the tenure clock, I always felt like I should be doing the items that earned more visibility. Our independent efforts are more private, so we let them become a lower priority. However, when independent efforts are successful, they actually earn more visibility and recognition than collaborative projects do. The best balance lies in being strategic by choosing to participate in projects that, when successful, will generate some tangible resources / benefits for you and your lab group. Lastly, while the Tenure \& Promotion process is becoming more collaboration friendly, it still remains very important to build your own credentials with your own independent projects and efforts.

\#4: Do attend proposal writing workshops whenever possible

Everyone who attends can learn a new tidbit every time. This is partially because there doesn't exist one optimal proposal structure / idea presentation strategy and because what reviewers look for evolves over time. Further, each agency has their own emphasis / desired presentation of the proposed project. Basically, to continue to secure funding, a person has to continually seek funding and continually learn how to best accomplish that task.

\#4: Don't attempt to plan research / write in a vacuum

The best way to learn and the quickest way to transition from unfunded proposals to funded proposals is to get feedback and help. It's true that trial and error learning is not the most efficient, but peer-review mechanisms dictate this. Most new faculty are acutely aware that they have a fixed timeline to attain funding, but shouldn't let this hinder their learning. Any given idea can get reviewed up to twice per year and with multiple project ideas in the pipeline, the probability of funding goes up substantially. Once an idea is funded, work on that project usually generates even more ideas and soon you'll have more ideas that you have time to write into proposals.

\section{\#5: Do read the RFP (Request for Proposals) carefully}

The RFP not only describes what the agency would like to fund, but it also lays out the ground rules for the proposal (length, content, etc.). For conformity and fairness, the agency must evaluate all proposals against the exact same criteria and formatting guidelines. It is important to identify key goals of the funding call and explicitly highlight how your project meets those goals in your proposal. If your proposal fails to conform, it will be "returned with out review", which is the worst possible outcome because not only has time elapsed, but you also do not have the valuable feedback on how to improve for the next submission. 
\#5: Don't pursue a “one size fits all" approach to writing proposals for various agencies / programs

The success rate of proposals goes down when the proposal is not adapted to the agencies needs. It is the PIs responsibility to convince the funding agency that what they are proposing is going to meet the needs of that agency and deliver upon project completion the information and outcomes that the agency desires.

\#6: Do believe (as you write) that your idea is innovative, novel, and unique (provided you've accrued evidence in \#1 \& \#2)

When a PI is really excited about an idea, it shows through in the proposal. Proposals that are enthusiastic, well organized, and thorough yield higher ratings and higher quality comments from reviewers. Writing that is dry is harder for reviewers to read; they are usually extremely busy and then don't take the time to provide the most useful comments. In general, when a proposal is bursting to "sell" your proposed idea and it addresses all the technical dimensions, it stands a very high chance of being funded.

\section{\#6: Don't allow yourself to get too big of an ego}

The advice in \#6 is a double-edged sword. If the proposal contains statements that belittle other research progress or is condescending to other researchers, this frequently elicits a "prove them wrong" type of response from the reviewers. The reviewer changes from being an advocate for either funding the proposal or for you by providing valuable feedback. Too much of an ego can set the wrong tone in the writing. As mentioned in \#2, every idea has shortcomings and too much of an ego while reading reviewers comments can keep you from "hearing" the advice provided by reviewers.

\#7: Do celebrate a submission and then begin planning the next proposal There is no greater feeling than having just finished up a large project that a) you were intimidated of doing for one reason or another and b) that you did your very best on and you're proud of the resulting product. Celebrate this accomplishment! It's a reward in and of itself even if the proposal is not funded. Then, start looking forward again and always have something in the pipeline (planning, under review, funded). Yes, even if you have a funded proposal, stick with this same strategy of keeping something in the pipeline. A wise mentor once told me, "If you are resting on your laurel's, then you are wearing them in the wrong spot."

\#7: Once the proposal is submitted, Don't place too much hope on that one document Enjoy celebrating the submission, but then forget about the document while it is under review. Our mind's memory tends to romanticize things and a person can start believing that the proposal they produced is the greatest thing since sliced bread. Remember that every idea has shortcomings and every review has a level of unpredictability. You may have misunderstood the focus of the RFP or there may be a large number of far more meritorious proposals in the pool that you are competing against. If you have worked on a couple of other proposal ideas in the meantime, you are refreshed and ready to revamp this one.

\#8: Do value and study the reviewers' comments when you are not funded It can be devastating / infuriating to read reviewers comments sometimes. I find it is best to read the reviews carefully, then leave them for a day / week. When I reread the comments, I usually 
see additional interpretations and can see the reviewer's perspective. The most common rebuttals are that the reviewer did not understand. Well, this is usually a shortcoming of the proposal more than it is a shortcoming of the reviewer. If a reviewer or two misunderstood, identify how you can rewrite to make the concepts clearer. The proposal needs to be organized and written in such a way that the key hypothesis and specific goals of the research are prominently communicated and re-iterated throughout. If reviewers identify a substantial flaw, directly address this in the next revision (don't try to hide it) and demonstrate an alternative approach which will answer the concern.

\#8: Don't remain hurt / angry and disregard the feedback

The most detrimental thing a new faculty can do while learning to write proposals is to harbor negative feelings, allow these feelings to cloud judgment, and disregard the feedback he or she just received. In the end, this type of thinking only hurts the new faculty. Writing proposals is a challenge and thinking of it as a game helps keep it in perspective. The first time any of us tried to play basketball, we likely didn't get the ball through the hoop very often. Practice and learning techniques improves the success rate. While trial and error is not the most efficient learning tool, it is necessary in the scientific / engineering community to develop project plans / proposals that are innovative, robust, and have a high probability of yielding successful results that advance the field.

\section{\#9: Do try and try again}

While every idea has shortcomings, the more important side of that is that every idea has merit. The challenge for the new faculty PI is to use the reviews to identify if a) the idea had too many flaws or b) your presentation of the idea was poor. Work to address each directly. For flawed ideas, identify the flaws prominently in the proposal, then clearly outline how you will address solutions or how you will control for these during your research. Presenting the idea and selling the idea to the reviewers and the funding agency can be learned by reading other examples and asking for help from colleagues (\#2) and attend workshops (\#4). Do your very best on those areas that you can influence ( $\mathrm{a}$ and $\mathrm{b}$ above) and simultaneously recognize that this is a probability game where you change the odds with superior planning. As with any game, enjoy the challenge and how it makes you better in your field.

\section{\#9: Don't ever give up!!}

It can be hard, but trust that you earned your job via your sound credentials and research talents. Believe in your ability to develop important ideas and strive to improve with each proposal you write. After a particularly brutal review, tell yourself, "I'm not a failure. I failed at something." There is a BIG difference. - Erma Bombeck

\section{\#10: Once funded, Do re-use your proposal}

In order to receive funding from competitive sources, it was necessary for you to communicate a well-developed project plan with justifications for every step in the project. This is an excellent project guide for your graduate student and a tool you can refer back to during the course of the research to remain focused. As quickly as possible, pull the literature search from the proposal into a publication that can either be a review article (if timely in the field) or a publication including the completion of preliminary data. For a CCLI, the first publication is usually 
dissemination to the larger community the current state of the curriculum and resources for improvements.

\section{\#10: Don't stop writing}

While writing the proposal, it can help to plan when you will publish on each project component. Reviewers for the funding agency like seeing this level of planning. Setting this as a milestone can help keep your student on track once the project is funded as well. Lastly, write additional proposals for unanswered questions that arise during the research. Be careful of this though, if it is too similar to the work you are already doing, the funding agency won't want to fund it and it is necessary to branch out more.

Combined, this list of 10 Dos and Don'ts can help a new faculty retain a positive, productive attitude as they develop proposal writing skills and grow their research / educational scholarship program.

\section{NSF CAREER Proposals}

The author's presentation in the "2575: Funding Sources for Engineering Research" session jointly sponsored by the New Engineering Educators Division and the Engineering Research Council also included some advice specific for writing NSF CAREER awards. The information from those slides is also included here.

This is a challenging proposal to write because it needs to include a full career plan for the new faculty member that includes both research and teaching. The research component is far more important than the educational component and will be scrutinized and discussed much more extensively by the reviewers. However, the educational component should not be overlooked because NSF is interested in funding a true integrated CAREER plan for the PI. That plan needs to answer a key scientific question that is exciting to the field and the students in that field. As was discussed in \#1, when writing your Background / Foundation, clearly articulate what knowledge is missing from the field that you are going to obtain as well as the intellectual merits of your idea. You'll want to thoroughly describe your plan to systematically test and correct the deficiency including preliminary data obtained from your newly established research lab. You'll also want to discuss the implications of your work for further research, industry, or technology applications. This is the key that ties your research into the broader impacts, which of course will include graduate / undergraduate student development, dissemination of your research results, and your educational plan.

Your educational efforts should tie into your research theme and also produce an intellectual product. Just as you do in research, you'll want to disseminate ideas and results. I'd recommend targeting two different age groups such as Professional Engineers and grade school students. Sell your educational ideas to the local school or PE society to partner with them and obtain support letters. The letters will be stronger and better focused if you write the initial drafts for your partner. Another idea is to propose to teach a new course. It is important to provide detailed outline of topics and plan how you'll disseminate that information more broadly (publications, distance ed, websites, etc.). Some new faculty feel they need to do everything with their educational efforts, but it should be similar to how you approach the research. You'll 
want to do something significant, strategically. As with your research, you'll want to show preliminary involvement that is focused along your proposed educational theme.

Some schools have high success rates for their new faculty earning CAREER awards. Usually this is because the department or institution has a formal peer-review of proposals that occurs before the PIs submit it. If your institution doesn't have this, refer to \#2 and arrange it yourself. Remember that there are three tries for the CAREER competition and so it is critically important to use feedback from NSF reviews. The advice in \#8 can help. Don't read reviews while your feelings are hurt. Take notes from the reviews and highlight frequency of comments to determine if what you proposed was a bad idea OR good idea poorly presented. Overall, you want to make sure that you clearly communicate specific goals of project (both research and education) in the Project Summary, in the Introduction, in the body of the proposal and in the Intellectual Merit / Broader Impact discussion at end of project description. Be consistent with your message and cross reference throughout the proposal (research to education and vice versa). Lastly, have fun both while writing and dreaming about the proposed project!

\section{Conclusions}

This paper strove to provide practical advice for new faculty learning to write competitive research and educational proposals. The overarching message is intended to be encouraging, while acknowledging the difficulties one faces, it is intended to empower the new faculty to utilize feedback and grow to secure the funding they seek.

One major counter-productive activity is to listen to stories with the theme, 'the system is unfair'. I've heard these stories from people who submitted a proposal, which (in their mind) was an excellent unflawed piece of work, and the reviewers just didn't understand (see \#8) or stories where someone resubmitted a proposal and followed exactly what the reviewers said and then the new set of reviewers contradicted what the first set had written. The bottom line is that no system is without errors and while there are times where the PI's proposal was unfairly judged or routed, these are the exception and not the rule. In general, peer-review of competitive proposals is accomplished in such a way that the most meritorious, well-planned, wellconceived, creative, novel ideas are funded. This is an important way to view the system because it is well within the new faculty member's control to be able to write a meritorious, wellplanned, well-conceived, creative, and novel proposal and so they should focus their efforts on doing just this. Writing a successful proposal that outlines a new research effort is an iterative process. Most of us cannot do this alone or on the first try, just as most of us have not had a paper accepted without revisions. The pre-tenure trial time gives a new faculty the time to try, try, and try again. Enjoy the learning experience and best wishes as you develop your own successful proposals and earn funding for your ideas! 


\section{Bibliography}

1."Survival Kit for New Engineering Educators." ASEE Prism Magazine. 30 - 34, October 1994.

2. Kelly, V.M., "Time out for some timely advice." ASEE Prism Magazine, 30 - 33, September 1995.

3. Brent, R., and R.M. Felder, "The New Faculty Member." Chemical Engineering Education, 32(3), 206-207, 1998.

4. Felder, R.M, and R. Brent, "Faculty Guide to Time Management," Personal Handout, 2001.

5. Felder, R.M. and R. Brent, "Random Thoughts - Getting Started." Chemical Engineering Education, 29(3), 166$167,1995$.

6. Felder, R.M., "Random Thoughts - Things I Wish They Had Told Me." Chemical Engineering Education, 28(2), 108-109, 1994.

7. Altiera, N.J., "The Tenure-Track Years." ASEE Prism Magazine, 42, September 2000.

8. Schwartz, A.T., R.D. Archer, A.K. El-Ashmawy, D.K. Lavallee, and R. Eikey. "And Gladly Teach: A Resource Book for Chemists Considering Academic Careers." American Chemical Society, 2004.

9. Wankat, P.C., and F.S. Oreovicz, "Teaching Engineering." McGraw Hill, Inc. New York, 1993.

10. McKeachie, W.J., "Teaching Tips: A Guidebook for the Beginning College Teacher." Eighth Edition, D.C. Heath and Company, Lexington, MA, (ISBN: 0-669-06752-0), 1986.

11. Davidson, C.I., and S.A. Ambrose, "The New Professor's Handbook: A Guide to Teaching and Research in Engineering and Science." Ankor Publishing Company, Inc., Bolton, MA, (ISBN: 1-882982-01-0), 1994.

12. Wankat, P.C, "The Effective, Efficient Professor: Teaching, Scholarship, and Service." Allyn \& Bacon, (ISBN: 0205337112), 2002.

13. Making The Right Moves: A Practical Guide to Scientific Management for Postdocs and New Faculty, Burroughs Wellcome Fund and Howard Hughes Medical Institute, http://www.hhmi.org/grants/pdf/labmgmt/book.pdf, accessed January 2005.

14. Linden, J., "The Contribution of Narrative to the Process of Supervising PhD Students." Studies in Higher Education, 24(3), 351-369, 1999.

15. Boice, R., "Advice for New Faculty Members: Nihil Nimus." Allyn and Bacon, Boston, (ISBN: 0-205-28159-1), 2000.

16. Chesler, N.C., P.B. Single, and B. Mikic, "On Belay: Peer-Mentoring and Adventure Education for Women Faculty in Engineering." Journal of Engineering Education, 92(3), 257-262, 2003.

17. Felder, Richard, "Impostors Everywhere." Chemical Engineering Education, 22(4), 168-169, 1988.

Proceedings of the 2010 American Society for Engineering Education Annual Conference \& Exposition Copyright@2010,American Society for Engineering Education 